\title{
Design and Mechanics Analysis of Moving Mechanism of Inspection Robot for Thin Coal Seam
}

\author{
Shang Deyong ${ }^{1,2}$, Zhao Jianwei ${ }^{*}, 1$ and Fan Xun ${ }^{1}$ \\ ${ }^{I}$ School of Mechanical Electronic and Information Engineering, China University of Mining and Technology (Beijing), \\ Beijing 100083, P.R. China \\ ${ }^{2}$ College of Mechanical and Electrical, Hebei University of Engineering, Handan, Hebei, 056038, P.R. China
}

\begin{abstract}
The inspection robot for thin coal seam can replace workers to make the daily inspection in fully mechanized mining surface. Based on the narrow and poor environment of thin coal seam, we designed a joint swing arm inspection robot, which is able to adapt to the unstructured terrain in a thin coal seam. The structure of the moving mechanism of the inspection robot has been designed. It can be realized that there are two DOF for moving on a single drive central axis through design of the shaft inside and shaft sleeve outside. The strength check and the modal analysis of the key parts of the moving mechanism such as the hollow shaft sleeve and the drive shaft, are made by Ansys Workbench. According to the analysis results, the maximum stress caused by internal load and external impact load is far less than the yield strength of the material. The modal shape diagram shows that, when the meshing frequency and the external excitation frequency are much less than the first-order natural frequency of the parts, there will be no resonance and noise. The analysis results show that the design is reasonable and reliable.
\end{abstract}

Keywords: Inspection robot, modal analysis, moving mechanisms, stress analysis, thin coal seam.

\section{INTRODUCTION}

In China, thin coal resources are rich and widely distributed, the reserves of which account for more than $20 \%$ of the national coal reserves. With the development of new mining technologies, new processes, mechanized mining mechanization and automation mining equipments, the automation and unmanned operation of the thin coal seam mining become an important research direction of mining industry at home and abroad.

Thin coal seam space is narrow, which makes the installation, maintenance and operation of equipments very difficult. In the mining surface of thin coal seam, the working conditions are poor, the labor intensity is high and the production efficiency is low. Meanwhile, there is surface ponding in the mining surface of thin coal seam. It is harmful to workers to work under these harsh conditions for long time. In order to reduce the labor intensity of workers, it is urgent to research and design an inspection robot working in the thin coal seam to replace the workers to carry out the routine inspections [1]. Meanwhile, it is dangerous for workers to check the conditions of coal wall or coal roof in the goaf. Thus, in order to improve the safety level and reduce casualties, it is important to develop a visual inspection robot adapting to the environment of fully mechanized mining surface in the thin coal seam to replace the workers.

\footnotetext{
*Address correspondence to this author at the School of Mechanical Electronic and Information Engineering, China University of Mining and Technology (Beijing), Beijing 100083, P.R. China; Tel: +86 13811417312; Fax: +861062325016; E-mail: shangdy1983@qq.com
}

\section{DESIGN REQUIREMENTS ON PERFORMANCE OF THE INSPECTION ROBOT}

In the process of mining thin coal seam, the natural condition is complicated and the surrounding environment is harsh. On the mining surface, the grooves gather too much water, and there are also obstacles, such as hydraulic support pedestals, movable jacks, cables, collapsed rocks and crushed coal. Mining roadways are narrow and rough with many faults and steep slopes. Because of complex underground road conditions, it is necessary that robots have strong abilities of climbing obstacles, avoiding obstacles and restoring the function of moving.

So it is necessary to develop a swing arm robot assembled with six crawlers. This robot can change its height to adapt to the requirements of different environments. As such, it can not only work with lower height in a narrow space, but also can adjust its height to climb the obstacles. In this way, the mobile robot's defect of poor adaptation to environment on the ground can be overcome [2-5].

Since the thin coal seam inspection robot often works in such bad environments as damp, complex terrain, many obstacles, combustible and explosive dust, a robot with specific function should have the following features:

1. With small size, compact structure, and light weight, and being convenient for a single person to carry with;

2. With climbing, ascending and obstacle-crossing functions;

3. With dustproof, waterproof and explosion-proof functions; 
4. With visual function;

5. With remote controlling function, etc.

In view of the above requirements, we have developed an inspection robot with articulated swing arms and crawlers, which is adaptable to the terrain environment of fully mechanized working surface in thin coal seam. As shown in Figs. $(\mathbf{1}, \mathbf{2})$, this kind of robot has a symmetrical structure, in which four same swing arms and a body together constitute its three-section structure. In order to improve the movement flexibility and the obstacle-crossing ability of the robot, the robot is controlled by 6 DC motors, and the middle portion is assembled with a control system, a transmission system, a battery and other equipments.

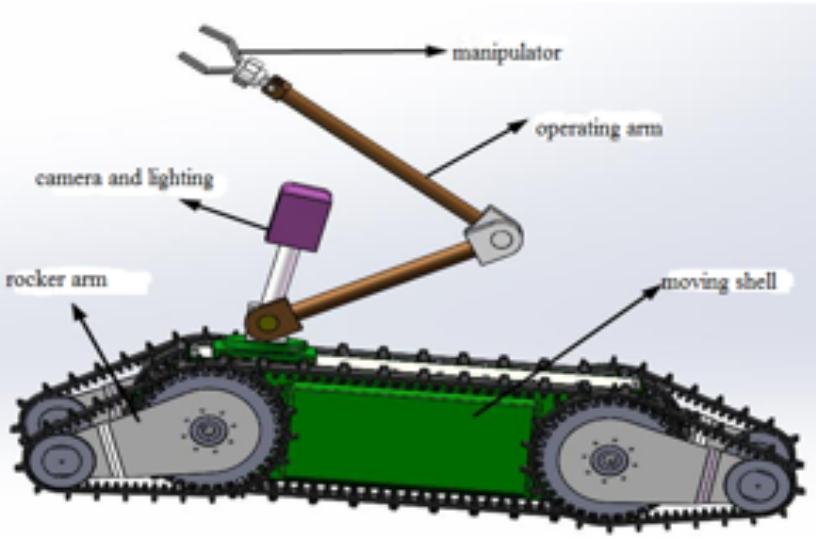

Fig. (1). Structural view of inspection robot.

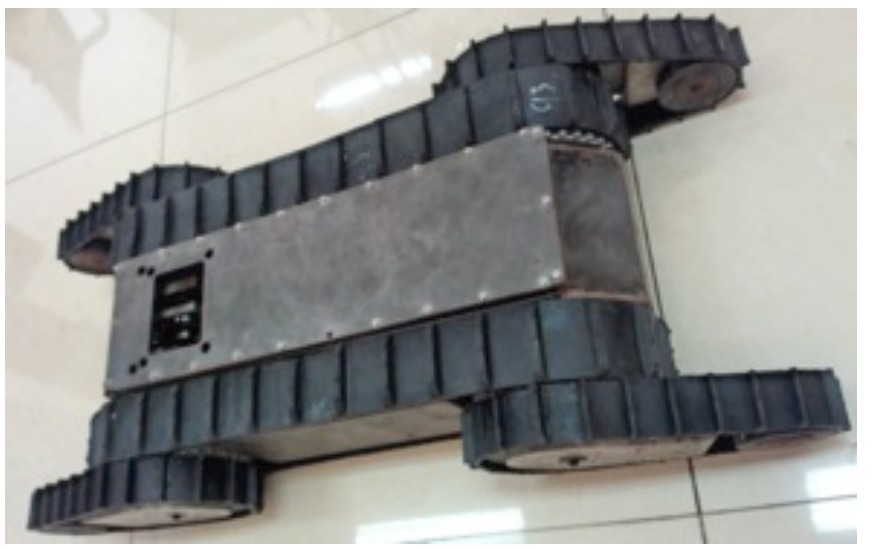

Fig. (2). Walking mechanism of inspection robot.

(1) The inspection robot has the characteristics of good flexibility, maneuverability and the capabilities of climbing and obstacle-crossing [6, 7], which is adaptable to all kinds of geographical environment of the worksite.

(2) The inspection robot can carry the gas sensor, temperature and humidity sensor, wind speed sensor, camera, lighting and manipulator, etc. in order to timely monitor some parameters of the fully mechanized working surface.

\section{DESIGN FOR MOVING MECHANISM}

The moving mechanism of the inspection robot includes its joint swing arms, which are the main parts used for crossing obstacles [8,9], and the sizes of which are determined by the maximum ability of crossing obstacles and its overall volume. The space of the fully mechanized working surface in thin coal seam is narrow, so the structure of the robot needs to be compact and the weight needs to be as light as possible, which puts forward strict requirements for the quality and size of the moving mechanism of the robot.

In the four articulated swing arms of the robots, the larger power motors drive the latter crawler wheels to rotate in order to realize the forward and backward movement of the robot. When the robot encounters obstacles, the smaller power motors will drive the swing arms to rotate in order to achieve the function of crossing obstacles. Since the transmission shafts of the swing arms and the crawler wheels are on a concentric shaft, it needs to be realized that the crawler wheels and the swing arms rotate together around the concentric shaft, namely realized 2-DOF motion. So the design employs the structure of inner and outer shafts and the way of hollow shaft sleeve transmission. The assembly diagram of the moving mechanism is shown in Figs. $(\mathbf{3}, \mathbf{4})$. After the drive motors for the swing arms reduce their speeds through the gears, the swing arms are connected to the transmission shaft by the keys to drive the transmission shaft to rotate, and then the transmission shaft is connected to the rocker-arm linkage by the keys. As such, it is realized that the motors for the swing arms drive the swing arms to rotate through the transmission shaft. After the main drive motor of the robot reduces its speed through the gear, the hollow shaft sleeve is connected by the key to rotate, and then the hollow shaft sleeve is connected to the main drive crawler wheels and the rocker crawler wheels by the keys again in order to achieve the rotations of the crawler wheels. The transmission shaft and the hollow shaft sleeves are at the same axis and rotate without interfering with each other through being born by two roller bearings. The position of the hollow shaft sleeve is determined by the positioning shaft. Under the condition of meeting load bearing, the inspection robot employs non-metallic materials with small density and light weight in order to meet the requirements for the light weight and portability. For example, the crawler wheels and the tensioning wheels are made by rubber polymer materials with high abrasion resistance and anti-impact capability, and the link rods of the swing arms employ aluminum alloy materials, while for the main parts bearing stress, such as the transmission shafts and the hollow shafts sleeve, employ alloy steel in order to meet the requirement for stiffness.

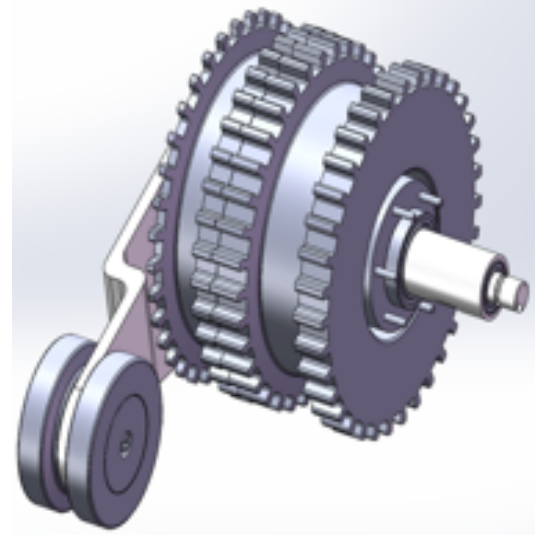

Fig. (3). 3D model for moving mechanism. 


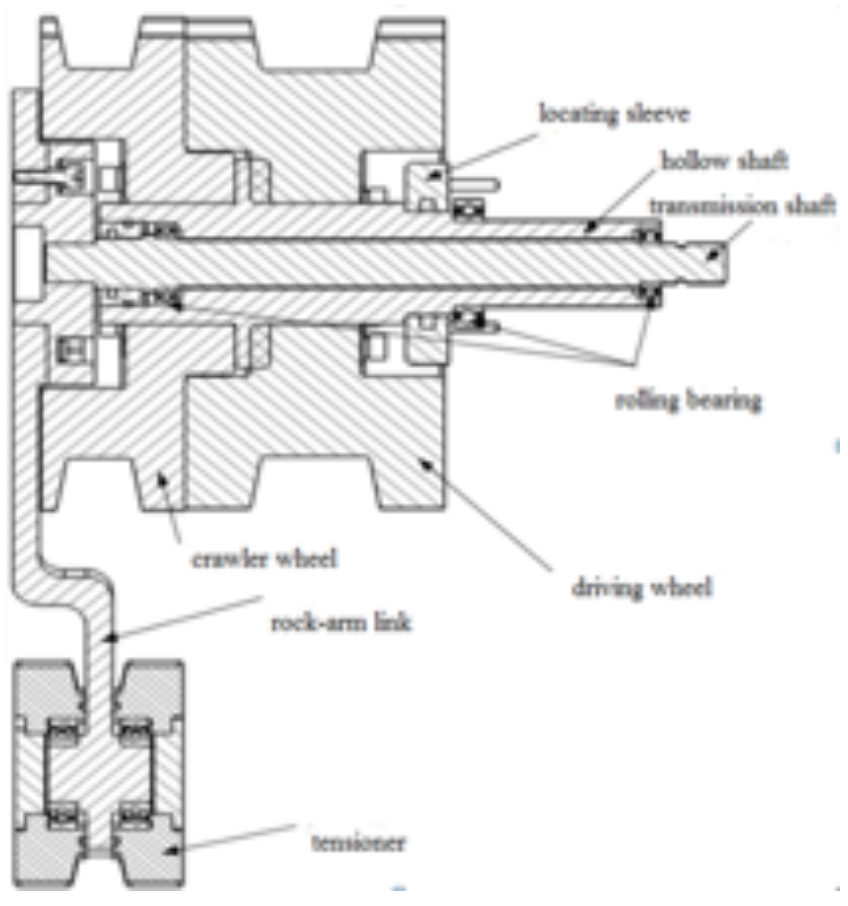

Fig. (4). Section view for moving mechanism.

\section{THE FINITE ELEMENT STRENGTH CHECK OF THE MAIN COMPONENTS}

The moving mechanism of the inspection robot has the important function of crossing obstacles. The latter swing arms bear the biggest impact load. When the robot crosses an obstacle, the latter swing arms support the whole body weight. In the moving mechanism, some parts, such as hollow shaft sleeve and transmission shaft, have special structures and are liable to be impacted by the external load. In order to ensure their reliability, it is necessary that stress strain analysis and strength check for these key parts should be done. This article uses the finite element analysis software Ansys Workbench to analyze these parts in order to guarantee about their reliability. Under the condition of ensuring that these parts are solid and durable, the sizes and weights of these parts are optimized in order to reduce the weight of the robot body.

With SolidWorks, the three-dimensional entity model of hollow shaft sleeve and transmission shaft are set up and then inputted into the Workbench. The material property is defined as alloy steel, the elasticity modulus $\mathrm{E}=2.07 \times 10^{11} \mathrm{pa}$, the Poisson ratio PRXY $=0.26$, the density $\rho=7800 \mathrm{~kg} / \mathrm{m}^{3}$ and the yield strength is $250 \mathrm{MPa}$. The gridding of the entity model is set as automatic mode, by which one of the greatest advantages is that the geometric grid division can be done separately, is achieved, instead of having to divide the whole model together like before. Obviously, the former is more flexible. The key parts are divided into tetrahedron units and the quality of dividing is inspected finally. The gridding finally formed is shown in Figs. $(\mathbf{5}, \mathbf{6})$.

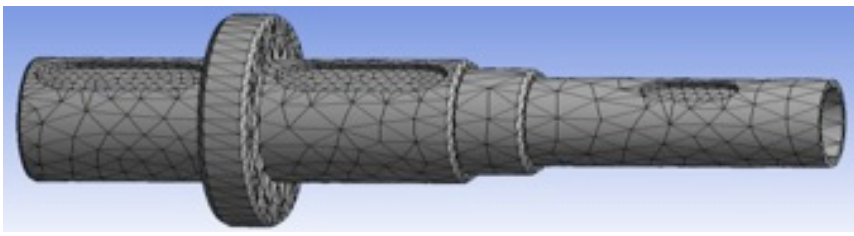

Fig. (5). Mesh generation of hollow shaft.

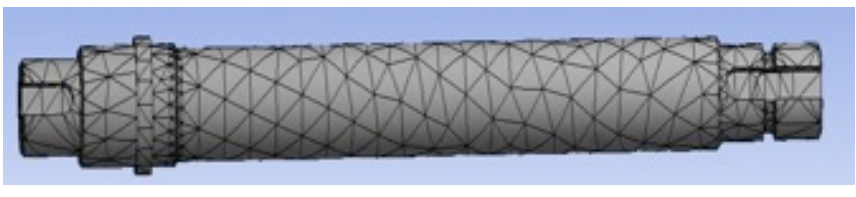

Fig. (6). Mesh generation of drive shaft.

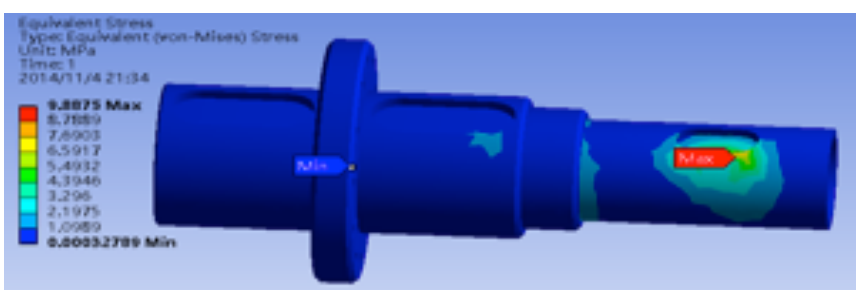

Fig. (7). Stress nephrogram of hollow shaft.

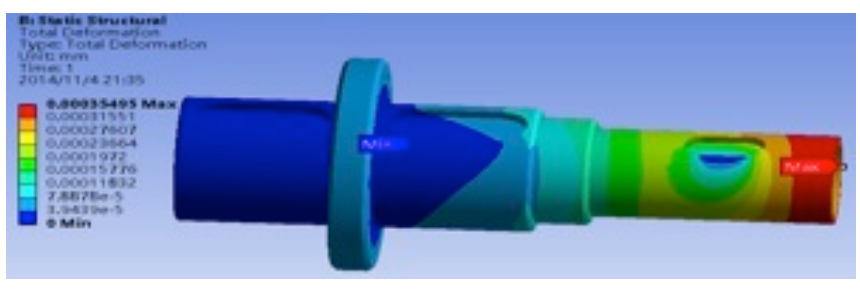

Fig. (8). Strain nephrogram of hollow shaft.

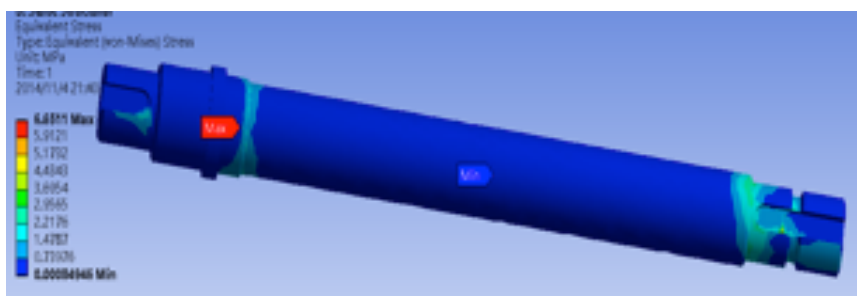

Fig. (9). Stress nephrogram of transmission shaft.

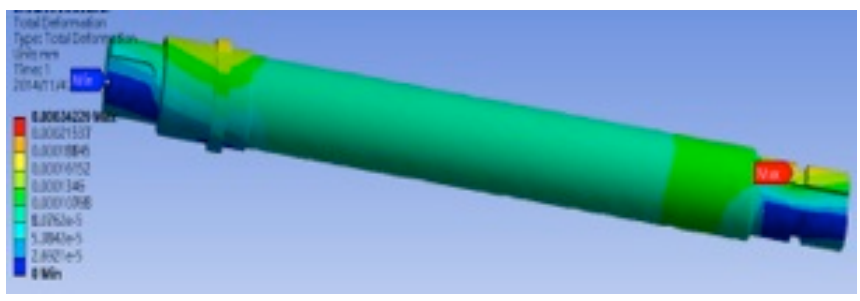

Fig. (10). Strain nephrogram of transmission shaft.

Whether the boundary conditions to be applied are consistent with actual engineering conditions, it would directly affect the correctness of the analysis results.

The following should be done to apply the load and constraint conditions to the hollow shafts and the transmission shafts: apply the bearing load to the bearing, set 
up the fix constraint at the contact surface between the keyways and the keys, apply the column constraint to the cylinder face, close the axial and radial freedom for tangential rotation and finally impose the torque load on the cylinder face of the shaft keyways. During design and calculation, bearing load and torque load need a certain safety allowance. The stress and strain nephrograms are shown in Figs. (7-10).

The analysis result shows that the values of the maximum stress and maximum strain of the designed hollow shaft and transmission shaft are far less than the allowed material damage value. Therefore, the safety and the reliability of the moving system of the robot are ensured.

\section{MODAL ANALYSIS OF THE MAIN TRANSMISSION PARTS}

The moving mechanism of the inspection robot is the main load-bearing mechanism. The transmission shaft and the hollow shaft are not only susceptible to internal impact from gear meshing; they would also be affected by the external complex excitation. When the frequency of the external excitation and the natural frequency of the shafts are equal or of integral times of each other, the resonance phenomenon would be caused. Its dynamic characteristics directly affect the overall performance of the robot, for example they influence assembly precisions of the gears and the shafts, increase the abrasions between the gears and the bearings, and reduce the service lives of these parts. Thus, it should be taken into consideration that the transmission shaft should avoid the main vibration frequency during design process of the moving mechanism to ensure good dynamic performance.

Modal analysis is the essential kinetics analysis and also the foundation of other kinetic analyses, such as random vibration analysis, response spectrum analysis and harmonic response analysis, all of which should be carried out on the basis of modal analysis, so it has extensive practical value. Ultimate goal of modal analysis is to identify the modal parameters of the system, in order to provide the reference for vibration characteristic analysis of the structure system, the vibration fault diagnosis and forecast, and the optimization design of structural kinetics characteristics [10].

In modal analysis, the analysis results are only associated with elastic modulus, Poisson ratio, density of material, and boundary conditions. Other external loads can be ignored. Hence, to do the modal analysis, only boundary conditions of the model should be restricted and external load would not be restricted.

This paper has extracted the front 4 orders result of modal analysis and observed the deformation conditions under the effect of each order. The strain nephrograms of each order are shown in Figs. $(\mathbf{1 1}, \mathbf{1 2})$.

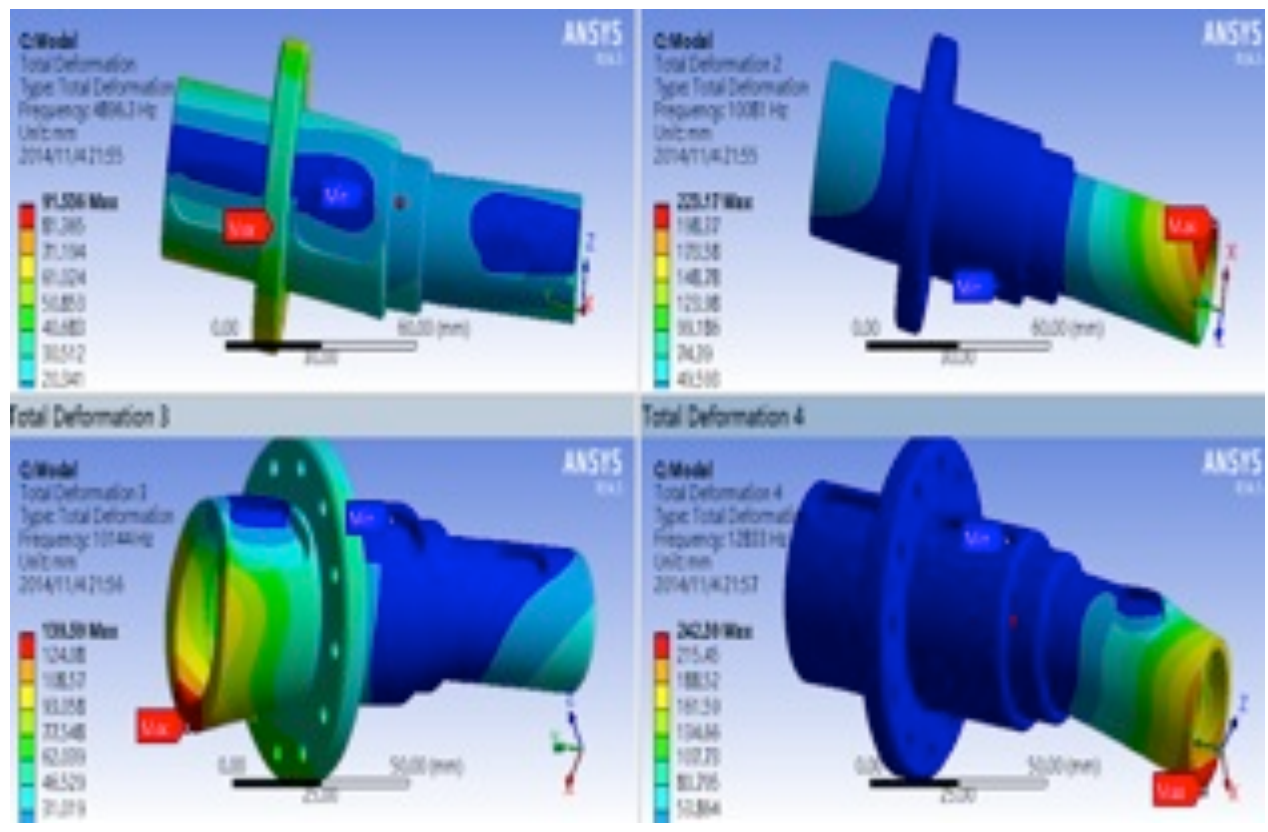

Fig. (11). The first four orders' vibration mode of hollow shaft.

Table 1. Characteristics of the first four orders' vibration mode of hollow shaft.

\begin{tabular}{|c|c|c|c|}
\hline Order & $\begin{array}{c}\text { Natural } \\
\text { Frequency/Hz }\end{array}$ & $\begin{array}{c}\text { Maximum } \\
\text { Deformation/mm }\end{array}$ & Description of Vibration Mode \\
\hline \hline 1 & 4896.3 & 91.536 & The hollow shaft bends seriously at contact surface with the bearing. \\
\hline 2 & 10081 & 223.17 & There is a serious deformation at the end of the hollow shaft. \\
\hline 3 & 10144 & 139.59 & There is a serious deformation at the head of the hollow shaft, and a flattening trend appears. \\
\hline 4 & 12833 & 242.39 & There is a serious deformation at the end of the hollow shaft, which is mainly the torsional deformation. \\
\hline
\end{tabular}




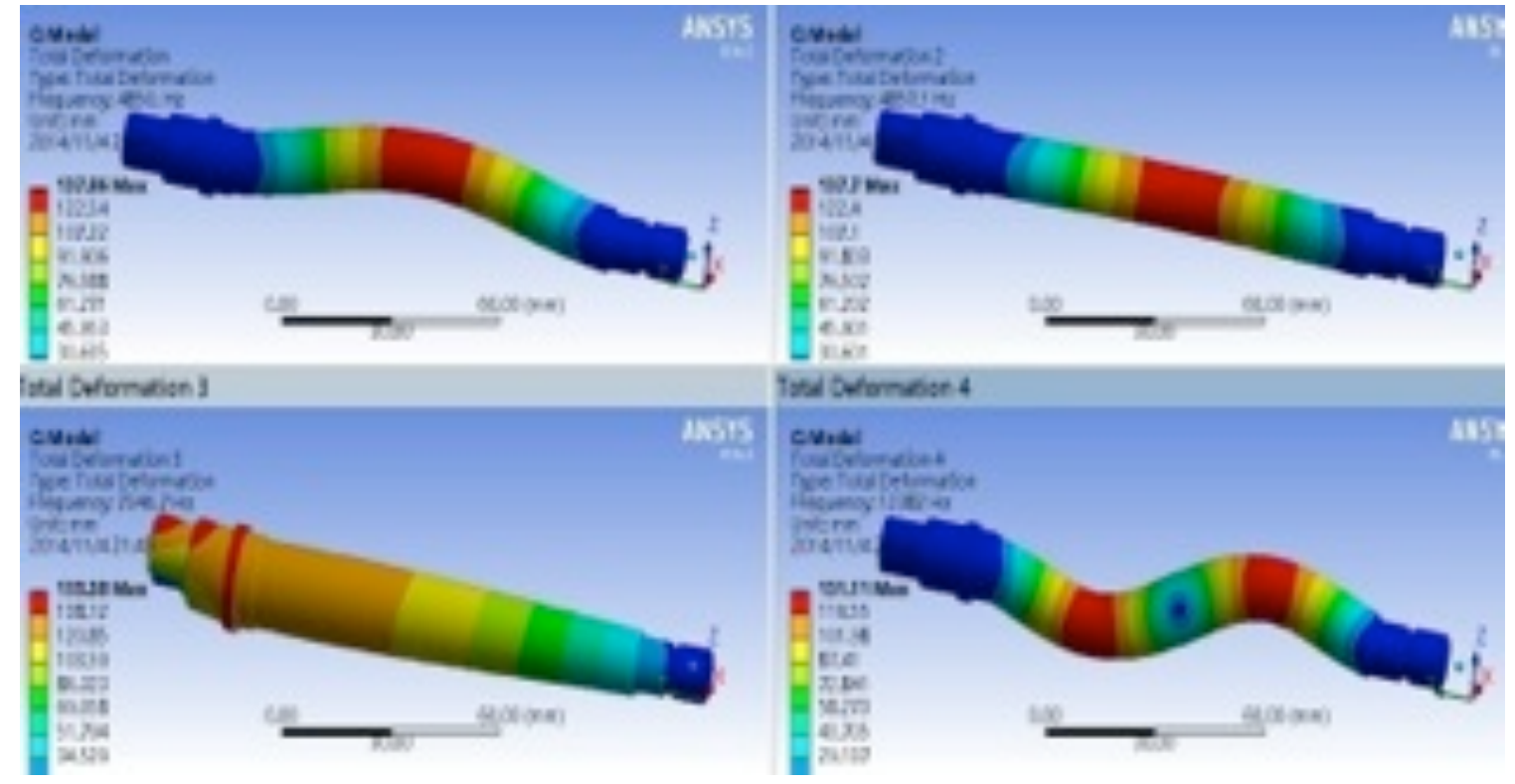

Fig. (12). The first four orders' vibration mode of drive shaft.

Table 2. Characteristics of the first four orders' vibration mode of drive shaft.

\begin{tabular}{|c|c|c|c|}
\hline Order & $\begin{array}{c}\text { Natural } \\
\text { Frequency/Hz }\end{array}$ & $\begin{array}{c}\text { Maximum } \\
\text { Deformation/mm }\end{array}$ & Description of Vibration Mode \\
\hline \hline 1 & 4850 & 137.86 & There is a serious deformation at the intermediate portion of the transmission shaft. \\
\hline 2 & 4857 & 137.7 & The deformation is similar to the $1^{\text {st }}$ order. \\
\hline 3 & 7346.7 & 155.38 & There is a serious deformation at the head of the transmission shaft. \\
\hline 4 & 12382 & 131.11 & There are serious bend and torsional deformation at the intermediate portion of the transmission shaft. \\
\hline
\end{tabular}

Experiments show that the vibration and noise of the moving mechanism are mainly caused by external excited force which stems from the gear mesh frequency and the outside bumpy ground. When the rotational frequency or frequency multiplication is close to the natural frequency of the transmission shaft, there will be a resonance of the shell, which causes the vibration and noise of the body. Both the main drive motor and the rocker drive motor employ the MAXON DC motor, the maximum rotary speed of which is $6000 \mathrm{r} / \mathrm{min}$ and the rotary frequency of which is $f=n / 60=100$ $\mathrm{Hz}$, and then the meshing frequency is between 0 and $100 \mathrm{~Hz}$ through gear reduction. The Tables $\mathbf{1}$ and $\mathbf{2}$ show that the natural frequencies of the first order of the hollow shaft and the transmission shaft are at high frequency stage and much greater than the meshing frequency, so the resonance and noise would not be caused. Under the condition of relatively poor road, the external excitation frequency also belongs to the low frequency range so that the body resonance wouldn't happen. Therefore, the reasonability of the design is validated.

\section{CONCLUSION}

This paper puts forward design of an inspection robot used for fully mechanized working face in thin coal seam, and sets forth the performance characteristics of the robot under the working environment in thin coal seam. The robot is composed of four swing arms and a body and is good at crossing obstacles and suitable for complex un-structural terrain underground coal mine.

The moving mechanism of the inspection robot has been designed. It employs the transmission form of the transmission shaft being assembled within the hollow shaft sleeve. It can realize 2-DOF movement of the rotation of the track wheel and the swing rotation of the swing arms at a single drive central axis.

The hollow shaft sleeve and the transmission shaft are the main transmission parts of the moving mechanism. Finite element method is used for their stress and strain analysis of respectively, and the results show that the parts can meet the strength requirements and thus verify the reliability of the design.

The modal analysis has been carried out about the hollow shaft sleeve and the transmission shaft, and the modals of the front four orders have been extracted. The results show that the natural frequency of the first order of both the hollow shaft and the transmission shaft are at high order, while the meshing frequency of the transmission system of both the moving mechanism and the external excitation frequency are low, so the vibration and noise of the system can't be caused, which also validates the reasonability of the design.

\section{CONFLICT OF INTEREST}

The authors confirm that this article content has no conflict of interest. 


\section{ACKNOWLEDGEMENTS}

This research was supported by National Natural Science Foundation of China (50775213) and Fundamental Research Funds for the Central Universities (2014QJ08).

\section{REFERENCES}

[1] Shang DY, Zhao JW. Research on kinematics joint type mobile robot platform for thin coal seam inspection. Appl Mechan Mat 2014; 650: 818-21.

[2] AIi S, Moosavian A, Kalantari A. Experimental slip estimation for exact kinematics modeling and control of a tracked mobile robot. 2008 IEEE/RSJ Int Conf Intelligent Robot Sys. Nice: France 2008; pp. $95-100$.

[3] Hirose S. Super mechano-system: New perspective for versatile robotic system. Proc $7^{\text {th }}$ Int Symp Exp Robot. Waikiki: Hawaii 2000; pp. 249-258.

[4] Kim JH, Lee CG, Kim G. Study of machine design for a transformable shape single-tracked vehicle system. Mech Mach Theory $2010 ; 45: 1082-95$.
[5] Lee W, Kang S, Kim M, Shin K. Rough terrain negotiable mobile platform with passively adaptive double-tracks and its application to rescue missions. Proc 2005 IEEE Int Conf Robot Automat, Barcelona: Spain 2005; pp. 1591-6.

[6] Mihankhah E, Kalantari A, Aboosaeedan E, Taghirad HD, AIi S, Moosavian A. Autonomous staircase detection and stair climbing for a tracked mobile robot using fuzzy controller. Proc 2008 IEEE Int Conf Robot Biomimetics. Bangkok: Thailand 2009; pp. 1980-5.

[7] Wang WD, Kong MX, Du ZJ. Analysis and motion planning for obstacle negotiation of tracked mobile robot. J Harbin Instit Technol 2009; 41(5): 30-6.

[8] Li YW, Ge SR, Zhu H. Obstacle-surmounting mechanism and capability of four-track robot with two swing arms. Robot 2010 32(3): 157-64.

[9] Duan XG, Huang Q, Li KJ. Design and motion analysis of miniature wheel-track-legged mobile robot. Chin J Mech Eng 2005; 41(8): 108-14.

[10] Han BH, Sun DG, Feng JP. Study on inherent vibration features of cutting gearbox casing applied on boom type road-header. Coal Sci Technol 2014; 42(1): 76-9.

(C) Deyong et al.; Licensee Bentham Open.

This is an open access article licensed under the terms of the Creative Commons Attribution Non-Commercial License (http://creativecommons.org/licenses/ by-nc/4.0/) which permits unrestricted, non-commercial use, distribution and reproduction in any medium, provided the work is properly cited. 